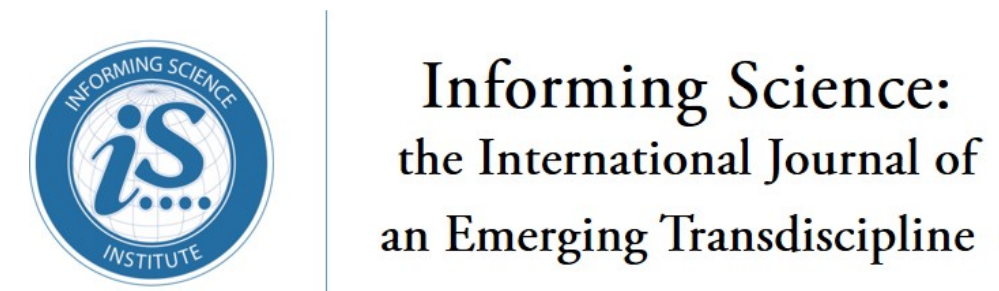

An Official Publication

of the Informing Science Institute

InformingScience.org

Inform.nu

Volume 23, 2020

\title{
UNIVERSITY-INDUSTRY COLLABORATION IN HIGHER EDUCATION: EXPLORING THE INFORMING FLOWS FRAMEWORK IN INDUSTRIAL PHD EDUCATION
}

Iréne Bernhard*

Anna Karin Olsson

* Corresponding author
University West, Trollhättan, Sweden

University West, Trollhättan, Sweden irene.bernhard@,hv.se

anna-karin.olsson@hr.se

\section{ABSTRACT}

Aim/Purpose

Background

Methodology

Contribution

Findings
The aim is to explore the informing flows framework as interactions within a $\mathrm{PhD}$ education practicing a work-integrated learning approach in order to reveal both the perspectives of industrial PhD students and of industry.

An under-researched field of university-industry collaboration is explored revealing both the perspectives of industrial $\mathrm{PhD}$ students and of industry.

Qualitative methods were applied including interviews and document studies. In total ten semi-structured interviews in two steps were conducted. The empirical context is a Swedish $\mathrm{PhD}$ program in informatics with a specialization in workintegrated learning.

By broadening the concept of work-integrated learning, this paper contributes empirical results on benefits and challenges in university-industry collaboration focusing on industrial $\mathrm{PhD}$ students and industry by applying the informing flows framework.

Findings expose novel insights for industry as well as academia. The industrial $\mathrm{PhD}$ students are key stakeholders and embody the informing flows between practice and university and between practice and research. They are spanning boundaries between university and industry generating continuous opportunities for validation and testing of empirical results and models in industry. This may enable increased research quality and short-lag dissemination of research results as well as strengthened organizational legitimacy.

[Accepting Editor Eli Cohen | Received: November 3, 2020 | Revised: December 2, 2020 | Accepted: December 3, 2020.

Cite as: Bernhard, I., \& Olsson, A. K. (2020). University-industry collaboration in higher education: Exploring the informing flows framework in industrial $\mathrm{PhD}$ education. Informing Science: The International Journal of an Emerging Transdiscipline, 23, 147-163. https://doi.org/10.28945/4672

(CC BY-NC 4.0) This article is licensed to you under a Creative Commons Attribution-NonCommercial 4.0 International License. When you copy and redistribute this paper in full or in part, you need to provide proper attribution to it to ensure that others can later locate this work (and to ensure that others do not accuse you of plagiarism). You may (and we encourage you to) adapt, remix, transform, and build upon the material for any non-commercial purposes. This license does not permit you to use this material for commercial purposes. 
Recommendations for Practitioners

Recommendations for Researchers

Impact on Society

Future Research

Keywords
This explorative study show that it is vital for practice to recognize that challenges do exist and need to be considered to strengthen industrial $\mathrm{PhD}$ programs as well as university-industry collaborations. Additionally, it is of importance to formalize a continuously dissemination of research in the industries.

Academia is recommended to recognize the value of the industrial $\mathrm{PhD}$ students' pre-understanding of the industry context in the spirit of work-integrated learning approach. The conditions for informing flows between research and practice need to continuously be maintained to enable short-term societal impact of research for both academia and industry.

This study contributes ways to reach short-term societal research impact through industrial $\mathrm{PhD}$ education that bridges and consolidates industry-university collaboration generating mutual learning and understanding.

Future international and/or transdisciplinary research within this field is encouraged to include larger samples covering other universities and a mix of industrial contexts or comparing industrial $\mathrm{PhD}$ students in different phases of their $\mathrm{PhD}$ education.

university-industry collaboration, industrial $\mathrm{PhD}$ education, work-integrated learning, third-cycle education, informing flows framework

\section{INTRODUCTION AND BACKGROUND}

Issues of digitalization and the pace of technological progress are vital societal challenges, especially the use of information technology throughout all sectors of society, and this needs to be recognized in university-society collaboration. In recent decades higher education in developed countries has experienced a rather demanding transformation towards increased interaction with industry, community, and governments (Altbach et al., 2019). Complex local and global societal challenges often need the inclusion of many perspectives and many problems are transdisciplinary in nature (Cohen, 2009). New forms of university collaboration with contemporary society are required. All levels of university programs and research need to meet societal challenges through education and research as well as various outreach approaches (De Jong et al., 2014; Galan, 2018; Larsson \& Holmberg, 2018; Lind et al., 2013) or industry-university course partnerships (Kock et al., 2000). Universities should also act as a provider of trained researchers, and there is increased interest in collaborative $\mathrm{PhD}$ education, i.e., third-cycle education (Borrell-Damian et al., 2010; Gill \& Mullarkey, 2015; Grimm, 2018; Gustavsson et al., 2016; Roolaht, 2015). Furthermore, there are calls for higher education to embrace an entrepreneurial approach (Giones, 2019, Klofsten et al., 2019) in order to inform society and act as knowledge hubs embedded in society (Bölling \& Eriksson, 2016; Gellerstedt et al., 2018; Gill et al., 2016; Lind et al., 2013; Olsson et al., 2020). Research impact and innovations are highly valued by governments, thus of crucial importance for universities (Altbach et al., 2019; Gellerstedt et al., 2018; Rampersad, 2015; Selsky \& Parker, 2005). Hence there is a demand for increased exchange of information in university-society collaborations in order to generate and disseminate new knowledge, research findings and innovations (Bölling \& Eriksson, 2016; Olsson et al., 2020) as well as for academia to understand industrial practices (Gill et al., 2016; Kihlander et al., 2011). However, translation of research findings into societal benefits and practice is lengthy and may take up to 10-17 years from research funding to publication (De Jong et al., 2014; Houghton et al., 2010; Morris et al., 2011). University research is expected to produce returns on investments, value, and applicable results for society and collaborations aiming for short-lag research impact are vital (Olsson et al., 2020).

One transdisciplinary approach to increase university-society collaboration is work-integrated learning (WIL). WIL is an umbrella term for various approaches and forms that integrate theoretical 
knowledge with practice work and bridge research, education and practice (Bates, 2008; Bernhard et al., 2018; Billett, 2009; Bowen \& Drysdale, 2017; Gellerstedt et al., 2015; Olsson et al., 2020; Patrick et al., 2008; Rampersad, 2015; Selsky \& Parker, 2005). In this paper WIL is viewed as research together with practitioners (Bernhard et al., 2018; Patrick et al., 2008; Rampersad, 2015). WIL is a model of collaboration that particularly focuses on knowledge exchange between university and society and the dual societal learning outcomes for the involved actors (Lundin et al., 2008). WIL has the potential to provide direct benefits not only for workplaces and universities, but also for a wider community as well as creating synergy between theory and practice (Arvemo et al., 2018; Gellerstedt et al., 2015). The WIL concept in higher education may be categorized as follows: (i) co-op, the traditional cooperative education model (Barbeau, 1973; Betts et al., 2009); (ii) case, using practice as inspiration; (iii) imprint, bringing practice to class; (iv) tools, using professional tools; and (v) field, bringing class to practice (Gellerstedt et al., 2015). Apart from the pedagogical benefits with experiential learning, WIL also maintains the transfer between higher education and practice (Olsson et al., 2019, 2020), and WIL students have career benefits regarding early career job advancement and higher salary (Gellerstedt et al., 2015). Although WIL is an umbrella term, the concept needs to adjust to the development in contemporary society and be broadened to include global perspectives on the future (Bowen \& Drysdale, 2017; Olsson \& Bernhard, 2020). An under-researched aspect of WIL is related to third-cycle education and the collaboration between university and industry through industrial $\mathrm{PhD}$ students as they are active in the university-industry interface (Bernhard \& Olsson, 2020; Olsson \& Bernhard, 2020). The concept of industrial PhD students here refers to students that originated from the industry and are fully employed in industry during their $\mathrm{PhD}$ education, i.e., the industry is investing in an employee to become a PhD doctorate. Accordingly, the industrial $\mathrm{PhD}$ students are at the same time involved in both the university and the industry, with the same academic demands as traditionally enrolled academic PhD students. They act as a channel or broker of knowledge spanning the boundaries between university and industry (Assbring \& Nuur, 2017; Berg \& McKelvey, 2020; Bernhard \& Olsson, 2020; Galan, 2018; Gustavsson et al., 2016; Kuntuu et al., 2018; Olsson \& Bernhard, 2020; Thune, 2009), hence also struggling with dual cultures and expectations (Bernhard \& Olsson, 2020; Kihlander et al., 2011).

In order to achieve deeper insights and analyze this kind of university-society collaboration from different perspectives, an informing flow framework, originating from Gill et al. (2016) is applied. This informing science framework is closely related to the WIL approach as it stresses transdisciplinary work and exchange of knowledge from one field to another in order to break down boundaries between collaborating actors that hinder the flow of knowledge by using information technology (see Cohen, 2009). The informing flow model for looking at business school informing channels has its overall aim to function as a strategic tool to identify and assess interactions related to informing channels and forms. This model is based on the premises of growing complexity of society and growing participant diversity of the stakeholders/clients being informed. In their framework the stakeholders/clients were categorized as the students, the research community, and the community of practicing managers that employ the students as the three most important stakeholders (Gill et al., 2016). In this paper the collaboration is viewed as a cross-fertilizing not only of disciplines but also of university and industry/theory and practice related to industrial $\mathrm{PhD}$ third-cycle education in informatics with the specialization in WIL. Focus is on informing flows as interactions between university and industry in $\mathrm{PhD}$ education identifying challenges and benefits that may affect these interactions. According to a previous case study (Bernhard et al., 2018), research on $\mathrm{PhD}$ program collaboration and work integrated learning through the lens of the informing flow framework, the interactions between university, students, research, and practice needs to be further developed.

There is however limited research on the benefits of university-industry collaboration regarding $\mathrm{PhD}$ education (Assbring \& Nuur, 2017; Bernhard et al., 2018; Bernhard \& Olsson, 2020; Olsson \& Bernhard, 2020; Roolaht, 2015), and it is mainly focused on the students' learning outcomes and educational experiences (Berg \& McKelvey, 2020; Thune, 2009). Emerging research covers, e.g., European 
industrial $\mathrm{PhD}$ programs in informatics and engineering in Sweden (Berg \& McKelvey, 2020; Kihlander et al., 2011), engineering and health science in Portugal (Tavares et al., 2020), engineering and automotive manufacturing in Germany (Grimm, 2018), programs as policy tools for university-society collaboration in Estonia and Denmark (Roolaht, 2015), and, in the USA, the interdisciplinary business doctorate program for executives (Gill \& Mullarkey, 2015). Furthermore, research on collaboration and strategic collaborative arrangements over time between industrial $\mathrm{PhD}$ students and industry is scarce (Kihlander et al., 2011).

As a response to calls for further research (e.g., Bernhard et al., 2018) the aim of this explorative study is to apply the informing flows framework on interactions within a $\mathrm{PhD}$ education program practicing a work-integrated learning approach. The benefits and challenges that may affect these interactions from both the perspectives of industrial $\mathrm{PhD}$ students and of industry are explored. The empirical context is a Swedish industrial $\mathrm{PhD}$ program in informatics with a specialization in workintegrated learning. The following research questions are thus addressed:

RQ 1: What are industrial $\mathrm{PhD}$ students' views on the $\mathrm{PhD}$ education collaboration? RQ 2: What are industry views on the $\mathrm{PhD}$ education collaboration?

Qualitative methodology was applied and ten semi-structured interviews with five industrial $\mathrm{PhD}$ students and five representatives from organizations (industry) were conducted.

\section{THEORETICAL FRAMEWORK}

As stated above, earlier research mainly focuses on the students' learning outcomes and educational experiences (Thune, 2009), although some benefits of this kind of collaboration are recognized (Assbring \& Nuur, 2017). Andersen et al. (2017) stress the importance of skills, planning, and communication to design and run a successful university-industry collaboration. Furthermore, trust, continuity, and long-term relationships between university and industry are vital for successful collaboration and societal impact (Olsson et al., 2020). The industrial benefits of a university-society collaboration may include collaboration for product or process development, access to academic networks, competence development/supply, and business opportunities (Berg \& McKelvey, 2020; Broström, 2012).

Recent research on impacts of industrial $\mathrm{PhD}$ education in Sweden show short-term impacts such as competence development, new or strengthened collaboration with universities and companies, legitimacy, technology transfer, and networks. The long-term impacts for industry are new business opportunities, industrial renewal/development, increased competitiveness, networks, and competence development and innovation capacity (Berg \& McKelvey, 2020; Gustavsson et al., 2016). Impacts for universities are, e.g., increased number of $\mathrm{PhD}$ students enrolled, strengthened collaboration with companies, boosting faculty competence development, new research collaboration and strengthened position within a research area nationally and internationally, development of doctoral education, and external research funding (Gustavsson et al., 2016). Kihlander et al. (2011) point out that to increase the probability that both academia and industry will view the collaboration as mutually rewarding, the various collaborative parties need to understand and cope with expectations and requirements placed on the industrial $\mathrm{PhD}$ student. Additionally, prerequisites identified as success factors for collaboration around industrial $\mathrm{PhD}$ education are, according to earlier research (Grimm, 2018; Gustavsson et al., 2016; Kihlander et al., 2011; Kolmos et al., 2008; Tavares et al., 2020), joint design and support of the program, aligned dual requirements, long-term organizational commitment from university and industry, and a supportive organizational structure. The collaboration and aims should be strategically anchored in both university and industry with transparent regular communication following the student's progress and joint supervision, design, and scope of $\mathrm{PhD}$ projects. Furthermore, careful recruitment of motivated students who may work in the interface between university and industry is vital. Organizational flexibility is important to provide the $\mathrm{PhD}$ student with flexibility and time to 
collaborate with colleagues in university and industry and to avoid isolation or high workload. However, the divergence between university and industry may cause dilemmas such as the different time horizons regarding research results, industry's need to keep data confidential, and the university's need to disseminate knowledge as article publications (Tavares et al., 2020).

A framework model for looking at business school informing channels developed by Gill et al. (2016) has its overall aim to function as a strategic tool to identify and assess resources spent on activities related to informing channels and forms. This model is based on the premises of growing complexity of the environment and growing participant diversity of the stakeholders/clients being informed. With this background, Gill et al. (2016) argue for a change in informing channels from not only relying on traditional lectures and traditional knowledge-based collaboration, but instead towards more interactive informing channels with increased emphasis on discussion and simulation, and on the construction of interactive exchange of information. In their framework the stakeholder/client category was reduced to the students, the research community, and the community of practicing managers that employ the students as the three most important stakeholders (Gill et al., 2016). Using this framework, slightly modified, findings from a study evaluating a $\mathrm{PhD}$ program (third cycle) and research environment from a WIL perspective (Bernhard et al. 2018) indicate that communication and interaction initiated from $\mathrm{PhD}$ students and research environment towards industry were generally strong, while in the opposite direction originating in practice was weaker. Collaboration activities were identified and visualized within and between the research education/environment and university key stakeholders as illustrated in Figure 1.

In order to embrace deeper insights into these results, a recent case study was performed identifying several informing flows between and within institution, research, practice, and student communities. All flows tended to go through the industrial PhD students (Bernhard \& Olsson, 2020).

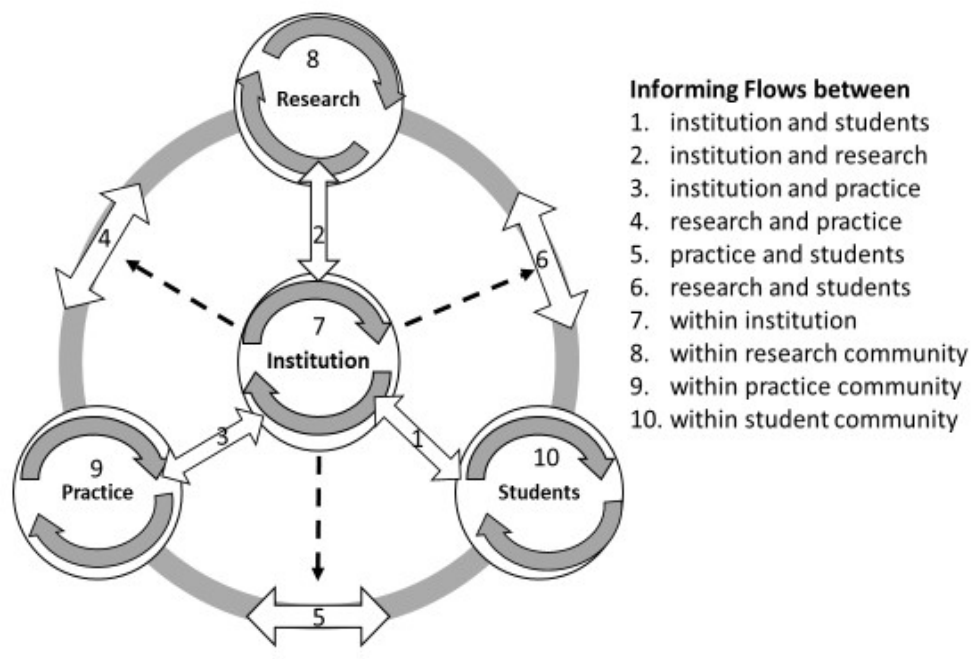

Figure 1. The stakeholders and the ten informing flows in the Informing Flows Framework. (Source: authors adapted from Gill et al., 2016, p. 7)

Thus, research on interaction and informing flows between university, students, research and practice needs to be further developed (Bernhard et al., 2018; Bernhard \& Olsson, 2020; Olsson \& Bernhard, 2020), especially the two-way exchange and mutual benefits of collaboration on $\mathrm{PhD}$ education (Gustavsson et al., 2016). 


\section{METHODOLOGY}

This research is conducted as an explorative case study, focusing on industrial $\mathrm{PhD}$ students and university-society collaborations within a Swedish doctoral program (third-cycle education) in the discipline of informatics with a specialization in work-integrated learning.

\section{RESEARCH CONTEXT}

This study is contextually drawn from higher education in Sweden. Across all Swedish universities 16,861 PhD students were enrolled in 2018 and of these 979 (almost 6 percent) as industrial students (Swedish Higher Education Authority, 2019). Doctoral education has been transformed along with societal needs and labor markets for PhDs, and $\mathrm{PhD}$ education does not merely aim for academic careers (Malfroy, 2011; Metcalfe, 2006). The design and funding of a PhD education show national variations; thus, the majority of $\mathrm{PhD}$ students are by tradition funded by universities and external funding. However, industry funding of $\mathrm{PhD}$ students is increasing and often also includes industry experts taking part in supervisory committees (Borrell-Damain et al., 2010).

The empirical research context is University West in Sweden, which is one of 31 public Swedish higher education institutions (Swedish Higher Education Authority, 2019) and has an overarching profile and basic principle applied to learning, research, the exchange of ideas, and educational development. University West took one of the first initiatives for supporting WIL in 1990 as the only university in Sweden to adopt cooperative education (co-op) in bachelor's programs. In 2002 University West was commissioned by the Swedish government to develop WIL as a pedagogical strategy. During 2011-2019 University West offered two doctoral degrees with specialization in WIL in the fields of informatics and pedagogy, which means that the PhD program is based on WIL not only as an aim for the research projects, but also as a pedagogical approach. There are both PhD students employed by the university as well as $\mathrm{PhD}$ students employed by industry, i.e., industrial $\mathrm{PhD}$ students who follow these doctoral degree programs. A Swedish $\mathrm{PhD}$ program corresponds to four years of full-time study comprising 240 ECTS credits (Swedish Higher Education Authority, 2019). In the Swedish context, the $\mathrm{PhD}$ students are enrolled in $\mathrm{PhD}$ education programs and required to take credit courses and write an independent thesis. This study concerns industrial $\mathrm{PhD}$ students enrolled in the informatics program with a specialization in WIL at University West that focuses on the use and development of information technology (IT) in the workplace. It deals with studies of the way IT affects learning, knowledge, and cooperation in the workplace. Informatics with a specialization in WIL is an interdisciplinary subject area with links to work organizational science, computer science, educational science, sociology, media and communication science, and cognitive science. For the doctoral degree, the courses comprise 90 ECTS credits (60 of which are in compulsory courses) and a thesis project comprising 150 ECTS credits.

\section{DATA COLLECTION AND ANALYSIS}

This study explores the informing flows framework on university-industry collaboration in higher education with focus on industrial $\mathrm{PhD}$ education in order to capture the perspectives of industrial $\mathrm{PhD}$ students and of industry. A qualitative methodology was applied, and individual semi-structured interviews were conducted in two steps to reveal (i) industrial $\mathrm{PhD}$ students' views on the $\mathrm{PhD}$ program and collaboration between research, university, and industry in autumn 2019, and (ii) industry's' views on investing in industrial $\mathrm{PhD}$ education and interaction between research, university, and industry in spring 2020. Furthermore, document studies were conducted as data was collected via the university administration from the industrial $\mathrm{PhD}$-students' official annual individual study plans for the $\mathrm{PhD}$ study programs in order to validate information about the $\mathrm{PhD}$ students, their employment, their study progress, their thesis project and scientific work, and contact persons at their organizations. Hence, in this qualitative, interpretive study, we aimed at striving for research rigor by selection of respondents, semi-structured and coded interviews, use of respondent validation and triangulation 
to confirm findings, and awareness of how to reduce researched bias (Gill \& Gill, 2020). Furthermore, a detailed documentation of all steps in the research process was conducted in order to enhance transparency replicability.

During 2020 the School of Business, Economics and IT, University West had five enrolled industrial $\mathrm{PhD}$ students and nine traditional academic $\mathrm{PhD}$ students within the field of informatics with a specialization in WIL. All five industrial PhD students participated; as mentioned above, they originate from and are fully employed in industry during their $\mathrm{PhD}$ education still following the same academic demands. They were however in different stages of their $\mathrm{PhD}$ education and represented different sectors of society. The respondents included three women and two men ranging in age from 37 to 50. Three of them are from the public sector and two from the private sector, representing industries such as health, education, IT consulting, and the furniture/design industry. Three of the respondents were in the beginning of the program, one respondent was in the middle, and one at the end as illustrated in Table 1. The percent of their PhD enrollment varied from 50 percent to 100 percent. Following research ethics and striving for research rigor (Gill \& Gill, 2020), we have not had any supervisory relationships with the industrial $\mathrm{PhD}$ students and their organizations, nor been serving on their thesis committees yet the authors of this article are employed at the same university. In order to make the industrial $\mathrm{PhD}$ students feel independence not affecting students' responses about their organizations we have offered and applied anonymity. The representatives from the organizations where the PhD-students are employed have not had access to the industrial PhD-students' interview transcripts.

Table 1. Overview of respondents

\begin{tabular}{|c|c|c|}
\hline Respondents & Sector & $\begin{array}{c}\text { Phase of PhD } \\
\text { Education }\end{array}$ \\
\hline $\begin{array}{l}\text { Industrial } \\
\text { PhD students }\end{array}$ & & \\
\hline R1 & Private & Beginning \\
\hline R2 & Public & Beginning \\
\hline R3 & Public & Middle \\
\hline R4 & Private & Beginning \\
\hline R5 & Public & End \\
\hline & & \\
\hline Organizations & & \\
\hline O1 & Private & \\
\hline O2 & Public & \\
\hline O3 & Public & \\
\hline O4 & Private & \\
\hline O5 & Public & \\
\hline
\end{tabular}

Two contact persons at each of the industrial $\mathrm{PhD}$ students' organizations (industries) were invited to participate in the second step of the data collection. In total five contact persons participated representing the public sector and the private sector. They had various experiences of employing and managing industrial $\mathrm{PhD}$ students. The selected organizations had from 1 to 55 employed industrial $\mathrm{PhD}$ students. The respondents had the following professional roles: research and development managers, operational managers, and senior advisor, almost all of them with an academic degree.

The interview guide for the industrial PhD-students covered four themes: (i) the benefits and the challenges being an industrial $\mathrm{PhD}$-student; (ii) if and how they perceived that their thesis project within the $\mathrm{PhD}$ education generated learning and new knowledge at the university and/or at the specific workplace (industry); (iii) the process and routines for knowledge exchange and knowledge transfer related to the $\mathrm{PhD}$ education at the workplace (industry), and (iv) their views of the overall collabora- 
tion between university and workplace (industry). The interview guide for the respondents at the organizations covered the following themes: their profession; their working role in the organization related to the industrial $\mathrm{PhD}$-student; the organizational benefits and challenges having an employee following the industrial $\mathrm{PhD}$-program; if and how they perceived that the thesis project of the industrial $\mathrm{PhD}$-student generated learning and new knowledge at their specific workplace (industry); the process and routines for knowledge exchange and knowledge transfer related to the $\mathrm{PhD}$ education at the workplace (industry), and their views of the overall collaboration between university and workplace (industry); if needed, what may be improved in the collaboration between the university and the organization; the approx. number of industrial $\mathrm{PhD}$-students employed within the organization.

Due to the respondents studying and or working in different contexts and due to the ongoing COVID-19 pandemic, the data collection was performed as a mix of face-to-face interviews, focus groups, telephone/Zoom semi-structured interviews in order to give voice to the respondents (see Linneberg \& Korsgaard, 2019), and as an email survey with open-ended questions with follow-up telephone interviews. The interviews were performed by the two researchers together and ranged from 20-40 minutes, were recorded with informed consent, transcribed, and coded. All transcripts of the face-to-face or telephone/Zoom interviews with $\mathrm{PhD}$-students have been validated by the respondents. The email surveys with respondents from the organizations have been followed up by telephone/Zoom interviews in order to validate their responses.

All collected data was analyzed in several rounds to identify patterns and recurring themes as well as contradictions, fulfilling the aim of this study (Alvesson \& Kärreman, 2007). As the data was collected in two steps, coding was also conducted in two cycles. Furthermore, an initial coding of all the data was done individually by each author using color markings and analytic memos to capture the ongoing researchers' reflections (Linneberg \& Korsgaard, 2019). Then the data was analyzed according to the pre-defined codes, i.e., the different flows in the informing flow framework (Gill et al., 2016) by the two authors together. The informing flow stakeholder categories applied in this study were all $\mathrm{PhD}$ students, the research community, the university, and the community of practicing managers (industry) who employ the industrial $\mathrm{PhD}$ students.

\section{FINDINGS AND DISCUSSION}

This section presents and analyzes findings of this study based on the two research questions.

\section{INDUSTRIAL PHD STUDENTS'VIEWS ON THE PHD EDUCATION COLLABORATION}

The respondents state several benefits they experience being industrial $\mathrm{PhD}$ students such as inclusion in academia as well as industry, being part of a research context and an industrial context with access to networks, and synergy effects related to empirical data and new knowledge as illustrated by the following quotes.

I think it is very good to have one foot in the organization [industry]. Partly because you keep your friends and workmates. You may continue to work in your work context and not lose that part. In my case, the health center is part of the research, which means that it gives me a lot of input for my research to work at the health center based on the fact that I am part of the research process when developing a test bed. I also try to look at myself as an "inspirer" being part of the research and the scientific way of thinking bringing it into work life and I know that it is not easy to have that focus in the daily work, but since I work 50-50 I can bring it to my workmates. (R2)

The advantage is that this can probably enrich both my dissertation and the results that I bring into the business. I have no difficulty whatsoever in gaining access to empirical data because there is a lot of it at my organization. (R1) 
The big advantage is the proximity to the empirical data, the accessibility to exciting projects and interesting people. There are synergy effects, working with development projects that generate data, which can and may be used for research purposes. (R5).

... to get to know a whole new research field and a research environment that I would not have known if I had not been accepted as a doctoral student. That has been a big advantage! After all, I have gained insight into knowledge that I would not otherwise have received, and this has opened up a new world in terms of what research already exists ... but also as a door opener to be part of a research environment. Not only do I need to read about other people's research, but I can actually take part in a research environment where I get to share my experiences, which means that I also get more benefit from what I get back. I see that as a very, very big advantage and it has expanded my networks a lot. (R3)

The mutual benefits are strongly emphasized by the respondents who are acting as channels or spanning boundaries between university and industry, corresponding to earlier research (see Assbring \& Nuur, 2017; Galan, 2018; Gustavsson et al., 2016; Kunttu et al., 2018; Thune, 2009). However, there are also challenges for industrial $\mathrm{PhD}$ students, expressed below as difficulty in focusing, changing roles, shortage of time, heavy workload, having to prioritize among tasks, and organizational lack of understanding of the design of the $\mathrm{PhD}$ program.

My employer has a hard time understanding that it is so labor intensive with taking courses and submission of assignments. (R1)

While it is a challenge to stay focused on the dissertation project when there are so many sidetracks - perhaps this is particularly challenging for research in informatics/Information Science that is close to practice and where conferences and publications are ranked high. It is about balancing and switching between different roles and sometimes contradictory perspectives and goals, e.g., what is in the interest of research, management, or patients. (R5)

As an industrial $\mathrm{PhD}$ student, there are many people you are responsible to and work towards [employers], I have R\&D [at the industry] that pays my doctoral position, and the university of course and it can be a bit fragmented since everyone wants you to be involved, partly to get involved and partly to have things there, but I have to try to stay focused even if I would like to be part of more. Because you need time for your research. There I can feel some guilty conscience towards the university and R\&D. Maybe you should have been there and met other $\mathrm{PhD}$ students both at the university and other industrial $\mathrm{PhD}$ students at my organization as well as the other staff who work there. (R2)

Another challenge that is stressed among the respondents is feeling alone and the fact that the benefit of belonging to both university and industry mentioned above is also experienced as a disadvantage.

Furthermore, the respondents highlight the work-integrated learning perspective when generating learning and new knowledge in industry although they state different experiences mainly due to their different stages in their $\mathrm{PhD}$ education.

The test bed itself is like an arena for learning and exchange of knowledge between both the academy, the companies, and the health center. The idea of the digital test bed is service design as method and that we should work with service design, which means that the staff is involved in the development of the products, i.e., one takes the staff's knowledge for help, and also, when it is relevant, one takes to some extent the patients' knowledge, which means that it will involve the staff to the greatest extent in the development, which makes it a knowledge-sharing activity. (R2)

The company has organized about ten internal and external lectures to inform about the project and to disseminate knowledge about the project's way of digitally addressing the 
problem we are investigating. A new business area has been started where the involved parties take part in the research and develop it further towards concrete products. It has been quite bad on the part of the university to catch up and do something about the project. (R4)

In addition, the respondent (R5) stresses that there has been a great deal of informal discussions and exchange in the daily work around the coffee table. Furthermore, there has been interest in the research by the respondent among colleagues at work as well as similar interest for the "job" among research colleagues at the university.

It has been an important signal value that my occupation exists. It is also important for the development of the health care that they chose to invest in funding a $\mathrm{PhD}$ education in Informatics/WIL which is not a traditional research PhD education within medical/health care research. (R5)

According to the respondents, some of the organizations have routines for knowledge exchange and follow-up of the $\mathrm{PhD}$ program. There are different organizational processes and routines for knowledge exchange of the industrial $\mathrm{PhD}$ students' education such as regular meetings, through different types of documentation and by taking part in the Individual Student Plan (ISP) prepared by the university.

Hence, findings show several informing flows (see Figure 1) that are supported related to the quotes above mainly as mutual flows between practice and students (flow no. 5), between research and students (no. 6), between research and practice (no. 8) as well as flows within the students' community (no. 10) and the practice community (no. 9). Since the industrial PhD students represent both student community and practice community these flows overlap accordingly.

\section{INDUSTRY VIEWS ON THE PHD EDUCATION COLLABORATION}

All respondents from industry were interested in increasing their collaboration with the university. They mentioned several benefits with the industrial $\mathrm{PhD}$ education collaboration, such as connecting university and industry, knowledge creation and dissemination, course partnerships, competence development, product development, and innovation as illustrated by the quotes below.

This is the ultimate way to build knowledge within a field! The PhD student builds contact paths between the organization and academia. An industrial $\mathrm{PhD}$ student has the cultural skills and is an "insider" who may find the current issues to study. (O3)

All businesses benefit from direct contact with academia and research. (O2)

In order to develop knowledge, methodology and company strategies our company needs researchers. This collaboration is very important to us and I hope that we will have more course partnership and more employees who will choose to become an industrial $\mathrm{PhD}$ student. (O1)

Within the R\&D unit [at the health care organization] we aim to create interest in and encourage activities for research and scientific work also within non-medical professions. (O5)

Continuity is vital since it takes time to develop really lasting relationships. It is important to have endurance. You also have to have contact and trust high up in the organization. It is important to access the strategic level because if the individual contacts you have at lower levels disappear, then everything can die. It is important to find places at different levels in the organizations where you have good contacts. One should not understand continuity only as personal continuity, but it is equally a structural continuity. (O3)

These organizational benefits are also recognized in earlier research (see Berg \& McKelvey, 2020; Broström, 2012; Gustavsson et al., 2016). Another benefit emphasized by one respondent was that the collaboration created legitimacy for the organization and products towards their customers. This is illustrated in the following quotation: 
The collaboration gives us a different perspective on our business development and new insights. It may also generate brand new products in the longer term and a way to market ourselves as a competence partner to our customers. (O4)

Some challenges were identified by the organizations. One of these was to find ways to integrate new knowledge in practice and to anchor the scope of the research project in practice and institution. Another one was the fear that the academic value in the PhD students' pre-understanding of the industry context is limited. Challenges regarding time limits for project results and workload were strongly emphasized and these correspond to earlier studies (Grimm, 2018; Gustavsson et al., 2016; Kihlander et al., 2011; Kolmos et al., 2008; Tavares et al., 2020).

The challenge lies mainly in the fact that the work tasks within the framework of the employment must have a close connection with the scope of the $\mathrm{PhD}$ thesis, and that the research results then will be able to be implemented in the current organization. (O5)

One challenge, but also an opportunity, is to be able to retain the strengths of both workintegrated learning and of professional knowledge and technology at the workplace. (O1)

One challenge that I have been pondering for many years is that as an industrial $\mathrm{PhD}$ student you are almost taught to deny that you have a very solid pre-understanding. It is in the traditional view of what it means to be a researcher to be able to be very distant and as objective as possible and all this. I agree with that on the one hand but on the other hand there are very many phenomena that cannot be studied unless subjectivity is allowed. You have to realize that some people have more prerequisites to be able to study certain phenomena because they are accepted as insiders in the organization and hence acting in a context where they understand what is happening. I think the insider perspective is as important as the outsider perspective ant that you need to integrate these two in research. (O3)

As it relates to research, it is a completely different setting for us since we are a sales organization. This means that we must remind ourselves that this really is research. It is a challenge to see a completely different timeline than we are used to. Another challenge may be being able to give enough time to the project and to the PhD student. (O4)

Then there is also an immaturity in the organization as today we have few managers who have a doctoral degree. Most managers do not understand the importance of writing a thesis and what will happen when you finish your PhD studies. (O3)

After all, we have many small, decentralized organizations that are too small to be able to carry the costs of an industrial $\mathrm{PhD}$ student as someone who is not completely "in production." What I am trying to work for, is to get this into some kind of organizational career development offered at a regional level, where one can work as a researcher and also be able to do other things in the organization ... it is slowly but surely moving forward ... and it is based on finding the right managers who want to address these issues and who are prepared to adapt career options to the individual employee. (O3)

Furthermore, keeping the employed industrial $\mathrm{PhD}$ student after graduation in the organization was highlighted as a future challenge:

One challenge is to be able keep the $\mathrm{PhD}$ student in the organization after graduation ... but most people still remain in the organization in some way - almost everyone changes role compared to the one they had before and that is probably not that strange. (O3)

Hence, findings show several benefits but also challenges that need to be considered in this kind of university-industry collaboration. Furthermore, one vital result from the study is that the organizations stress that already during their ongoing $\mathrm{PhD}$ education the industrial $\mathrm{PhD}$ students generate learning and new knowledge such as innovations, new products and new work processes in the organizations based on studies and empirical data as illustrated in the following quotes: 
The industrial $\mathrm{PhD}$ project gives us new knowledge. It also gives us knowledge in product development based on research data. (O4)

To a very high degree in a number of beneficial effects for the organization such as the work environment and the desire to find innovative ways of performing operative work. (O2)

Learning is generated through proximity, continuity, knowledge making, and bridge-building principles. (O3)

Findings also show that the dissemination of research results is performed at the workplace during everyday operative work as well as regular workplace meetings and seminars for colleagues, and as international and national publications.

The PhD student and I work closely together with product development in our organization and it is obvious that what our student learns in the third-cycle education affects our competence products positively. We also have formal reconciliation once a year with top management at our organization when the Individual Study Plan within the $\mathrm{PhD}$ program is discussed, informed and followed-up. (O1)

Dissemination of results is mainly done at workplace meetings. (O2)

We have regular seminars where we share what we are doing. It is a way to do that and then we always encourage the $\mathrm{PhD}$ students to involve their immediate surroundings in a very clear way and regularly present and discuss what they are working with. Because we know that if you do not have your closest manager with you and colleagues on your side, then you will get a lot more work. (O3)

I think that collaboration is strongly related to the concept of work-integrated learning. When you collaborate a lot and have a common goal formulation or research question, then you get many validation opportunities that one does not have otherwise. This collaboration enables one to really test and see if one is on the right path ... there can be completely different cycles when you perform research in strong collaboration. There are, of course, risks and weaknesses but I believe above all that it creates great added value since it provides benefits and what is of interest for society. (O3)

Direct research results are reported through studies, publications and national/international presentations. (O5)

Notably, findings show both short-term and long-term dissemination of research results and learning at the workplace/practice, partly in contrast to earlier research (Malfroy, 2011; Metcalfe, 2006). There are formal and informal organizational ways and informal flows to spread and discuss new knowledge and to involve colleagues in the $\mathrm{PhD}$ project. Furthermore, the continuous dissemination of research results at the organizations offers important opportunities for validation and testing of results for the industrial $\mathrm{PhD}$ students.

To sum up, applying an informing flows framework on a $\mathrm{PhD}$ education collaboration with focus on industrial $\mathrm{PhD}$ students generates several strong informing flows which were identified between and within university, research, practice, and student communities. Unlike earlier research (Bernhard et al., 2018) informing flows originating in practice were strong due to the industrial $\mathrm{PhD}$ students and their unique position both in industry and academia.

Additionally, in further development of the Informing Flows Framework (Gill et al., 2016), the industrial $\mathrm{PhD}$ students may here be viewed as key stakeholders in the model since they are both overlapping and bridging the boundaries between communities of research, practice, students, and university, as illustrated in Figure 2. Most informing flows to and from stakeholders go through the industrial $\mathrm{PhD}$ students having a central role in university-industry collaboration. The industrial $\mathrm{PhD}$ students thus embody the informing flows between practice and institution (university) see flow no. 3 in Figure 1; and between practice and research, see flow no. 4 in Figure 1. Furthermore, they are part 
of informing flows within practice, research, and student community, see flows no. 8, 9, 10 in Figure 1.

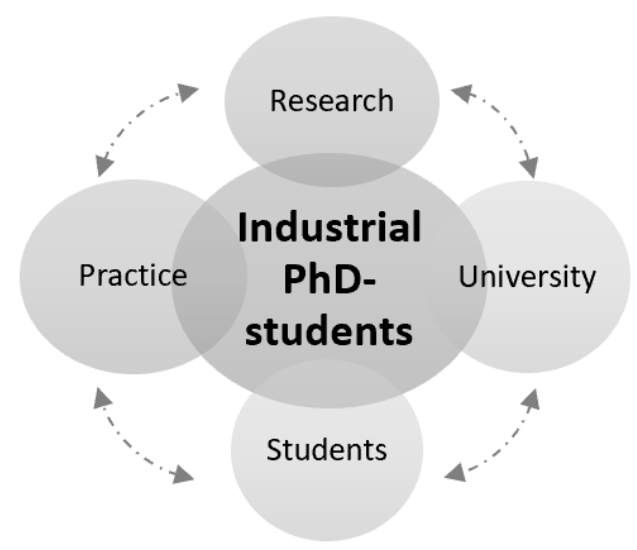

Figure 2. A WIL-based model for Informing Flows of industrial PhD education

\section{CONCLUSION}

This explorative study has sought to advance the current knowledge of university-industry collaboration in third-cycle education by applying the informing flows framework on interactions within a $\mathrm{PhD}$ education collaboration in order to answer the two research questions by revealing both the perspectives of industrial $\mathrm{PhD}$ students as well as of the industry.

By doing this, a work-integrated learning approach is applied on university-industry collaboration in higher education. Hence, this study contributes to broaden the WIL concept to also include the category of industrial PhD education. Accordingly, by applying the lens of work-integrated learning on industrial $\mathrm{PhD}$ programs, we state that the WIL concept in higher education should include all the following categories: (i) co-op, (ii) case, (iii) imprint, (iv) tools, (v) field, and (vi) industrial PhD education.

\section{IMPLICATIONS}

From our findings, the following implications on interactions between university and industry have been identified, here merely viewed as tendencies due to the explorative nature of the study.

- Several informing flows were identified between and within university, research, practice, and student communities, all viewed as aspects of work-integrated learning as stated above.

- Unlike earlier research, flows originating in practice were strengthened due to the industrial $\mathrm{PhD}$ students and their unique position both in industry and academia. Most informing flows to and from communities of research, practice, and university go through the industrial $\mathrm{PhD}$ students, and they hence have a central role in university-industry collaboration, see Figure 2.

- There are several benefits for industrial PhD students such as inclusion in academia as well as industry, being part of a research context and an industrial context with access to networks, and synergy effects related to empirical data and new knowledge.

- There are challenges for industrial $\mathrm{PhD}$-students that demonstrate the need of further increased communication and continuous flows as interactions between university and practice during the entire $\mathrm{PhD}$ education.

- The industrial PhD-students are acting as channels or spanning boundaries between university and industry generating continuous opportunities for validation and testing of empirical 
results and models in industry. This may enable increased research quality and short-lag dissemination of research results as well as strengthened organizational legitimacy.

- There are flows of research results through formal and informal organizational processes that improve disseminations of new knowledge. Industrial colleagues have the opportunity to be involved in the $\mathrm{PhD}$ projects, e.g., during operative work, workplace meetings, seminars, and in publications.

- The continuous flows between and within university, research, practice, and student communities, hence, enable short-term societal impact of research, e.g., ripple effects as flows of research knowledge and methods from institution and research to practice.

- Findings show that the industrial $\mathrm{PhD}$ students already during their ongoing $\mathrm{PhD}$ education generate flows of learning and new knowledge, such as competence development, new products, new work processes and innovations in the organizations.

\section{RECOMMENDATIONS}

This explorative study is a first step that may pave the way for future studies as it contributes novel insights for industry as well as for academia. The focus on the informing flows between university and industry may generate short-term societal research impact through industrial $\mathrm{PhD}$ education especially in informatics with $\mathrm{PhD}$ students from various industries and sectors. The industrial $\mathrm{PhD}$ students are bridging and consolidating industry-university collaboration. Consequently, this kind of university-industry collaboration is generating transdisciplinary and mutual learning and understanding across sectors and across industries. Long-term effects of this kind of work-integrated learning collaboration may result in stronger relationships, building on trust as well as breaking down organizational boundaries between industry and academia.

Based on the present findings of this explorative study, it is vital for practice to recognize that challenges do exist and need to be considered to strengthen industrial $\mathrm{PhD}$ programs as well as university-industry collaborations; to integrate new knowledge in practice; to anchor the scope of the industrial $\mathrm{PhD}$ students' thesis in practice and in research; to understand industrial $\mathrm{PhD}$ students' workload and time-limits; and to keep the graduated $\mathrm{PhD}$ students as employees within the organization. Additionally, we argue that is of importance to formalize a continuous dissemination of research at the workplace.

As in practice, we recommend that academia needs to recognize the value of the industrial $\mathrm{PhD}$ students' pre-understanding of the industry context in the spirit of the work-integrated learning approach. The conditions for informing flows between research and practice need to continuously be maintained to enable short-term societal impact of research for both academia and industry.

\section{LIMITATIONS AND FUTURE STUDIES}

There are limitations of this explorative study due to the single case and the number of respondents. Future international and/or transdisciplinary research within this field is encouraged to include larger samples covering other universities and a mix of industrial contexts or comparing industrial $\mathrm{PhD}$ students in different phases of their PhD education.

\section{REFERENCES}

Altbach, P. G., Reisberg, L., \& Rumbley, L. E. (2019). Trends in global higher education: Tracking an academic revolution. Brill. https://doi.org/10.1163/9789004406155

Alvesson, M., \& Kärreman, D. (2007). Constructing mystery: Empirical matters in theory development. Academy of Management Review, 32(4), 1265-1281. https://doi.org/10.5465/amr.2007.26586822 
Andersen, K., Thorste(insson, S. E., Thorbergsson, H., \& Gudmundsson, K. S. (2017). Developing the academic-industrial partnership through student research and projects: Case studies from Iceland. In 2017 IEEE International Professional Communication Conference (ProComm) (pp. 1-5). IEEE. https://doi.org/10.1109/ipcc.2017.8013930

Arvemo, T., Bernhard, I., Lundh Snis, U., Olsson, A. K., \& Torsein, E. (2018). Lessons learned from a crosssector development project: An integrative research approach. 12th International Technology, Education and Development Conference (pp. 3914-3922). https://doi.org/10.21125/inted.2018.0760

Assbring, L., \& Nuur, C. (2017). What's in it for industry? A case study on collaborative doctoral education in Sweden. Industry and Higher Education, 31(3), 184-194. https://doi.org/10.1177/0950422217705245

Barbeau, J. E. (1973). Cooperative education in America -Its historical development, 1906-1971 [Doctoral Dissertation, Northeastern University, Boston, MA].

Bates, M. (2008). Work-integrated curricula in university programs. Higher Education Research \& Development, 27(4), 305-317. https://doi.org/10.1080/07294360802406775

Berg, K., \& McKelvey, M. (2020). Exploring industrial PhD students and perceptions of their impact on firm innovation. In I. Bernhard, U. Gråsjö, \& C. Karlsson (Eds.), Diversity, innovation and clusters (pp. 125-156). Edward Elgar Publishing. https://doi.org/10.4337/9781789902587.00011

Bernhard, I., Lundh Snis, U., Gellerstedt, M., \& Svensson, L. (2018). Collaboration model for work-integrated learning in higher education 3rd cycle. 12th International Technology, Education and Development Conference March 5th-7th, 2018, Valencia, Spain (pp. 5509-5515). INTED. https://doi.org/10.21125/inted.2018.1302

Bernhard, I., \& Olsson, A. K. (2020). Work-integrated learning and collaboration in higher education 3rd cycle: The case of industrial PhD students. Proceedings of INTED2020 14th International Technology, Education and Development Conference March 2nd-4th, 2020, Valencia, Spain (pp. 2344-2353). https://doi.org/10.21125/inted.2020.0714

Betts, K., Lewis, M., \& Dressler, A., \& Svensson, L. (2009). Optimizing learning simulation to support a quinary career development model. International Journal of Work-Integrated Learning, 10(2), 99.

Billett, S. (2009). Realising the educational worth of integrating work experiences in higher education. Studies in Higher Education, 34(7), 827-843. https://doi.org/10.1080/03075070802706561

Bölling, M., \& Eriksson, Y. (2016). Collaboration with society: The future role of universities? Identifying challenges for evaluation. Research Evaluation, 25(2), 209-218. https://doi.org/10.1093/reseval/rvv043

Borrell-Damian, L., Brown, T., Dearing, A., Font, J., Hagen, S., Metcalfe, J., \& Smith, J. (2010). Collaborative doctoral education: University-industry partnerships for enhancing knowledge exchange. Higher Education Policy, 23(4), 493-514. https://doi.org/10.1057/hep.2010.20

Bowen, T., \& Drysdale, M. T. B. (Eds.) (2017). Work-integrated learning in the 21st century: Global perspectives on the future. Emerald Publishing.

Broström, A. (2012). Firms' rationales for interaction with research universities and the principles for public cofunding. The Journal of Technology Transfer, 37(3), 313-329. https://doi.org/10.1007/s10961-010-9177-4

Cohen, E. (2009). A philosophy of informing science. Informing Science: The International Journal of an Emerging Transdiscipline, 12, 1-15. https://doi.org/10.28945/425

De Jong, S., Barker, K., Cox, D., Sveinsdottir, T., \& Van den Besselaar, P. (2014). Understanding societal impact through productive interactions: ICT research as a case. Research Evaluation, 23(2), 89-102. https://doi.org/10.1093/reseval/rvu001

Galan, N. (2018). One foot in industry, the other in academia. Baltic Journal of Management, 13(4), 433-450. https://doi.org/10.1108/BJM-11-2017-0358

Gellerstedt, M., Bernhard, I., Lundh Snis, U., \& Svensson, L. (2018). Work-integrated learning: Increasing societal impact by decreasing the gap between research and practice. In 11th annual International Conference of Education, Research and Innovation, Seville (Spain). 12th-14th of November, 2018 (pp. 9337-9345). https://doi.org/10.21125/iceri.2018.0732

Gellerstedt, M., Johansson, K., \& Winman, T. (2015). Work integrated learning - A marriage between academia and working life. Journal of Systemics, Cybernetics and Informatics, 13(6), 38-46. 
University-Industry Collaboration in Higher Education

Gill, T. G., \& Gill, T. R. (2020). What is research rigor? Lessons for a transdiscipline. Informing Science, the International Journal of an Emerging Transdiscipline, 23, 47-76. https://doi.org/10.28945/4528

Gill, T. G., \& Mullarkey, M. (2015). The interdisciplinary business doctorate for executives: A novel way to bridge academic research and practice. Systemics, Cybernetics and Informatics, 13(6), 116-121.

Gill, T. G., Mullarkey, M., Mohr, J. E., \& Limayem, M. (2016). Building an informing business school: A case study of USF's Muma College of Business. Informing Science: the International Journal of an Emerging Transdiscipline, 19, 1-73. https:// doi.org/10.28945/3428

Giones, F. (2019). University-industry collaborations: An industry perspective. Management Decision, 57(12), 3258-3279. https://doi.org/10.1108/MD-11-2018-1182

Grimm, K. (2018). Assessing the industrial PhD: Stakeholder insights. Journal of Technology and Science Education, $8(4), 214-230$.

Gustavsson, L., Nuur, C., \& Söderlind, J. (2016). An impact analysis of regional industry-University interactions: The case of industrial PhD schools. Industry and Higher Education, 30(1), 41-51. https://doi.org/10.5367/ihe.2016.0291

Houghton, J., Rasmussen, B., \& Sheehan, P. (2010). Economic and social returns on investment in open arcbiving publicly funded research outputs. SPARC Report. https://core.ac.uk/download/pdf/30681781.pdf

Kihlander, I., Nilsson, S., Lund, K., Ritzén, S., \& Norell Bergendahl, M. (2011). Planning industrial PhD projects in practice: Speaking both 'academia' and 'practitionese'. In DS 68-8: Proceedings of the 18th International Conference on Engineering Design (ICED 11), Impacting Society through Engineering Design, Vol. 8: Design Education, Lyngby/Copenhagen, Denmark, 15-19 August 2011.

Klofsten, M., Fayolle, A., Guerrero, M., Mian, S., Urbano, D., \& Wright, M. (2019). The entrepreneurial university as driver for economic growth and social change-Key strategic challenges. Technological Forecasting and Social Change, 141, 149-158. https://doi.org/10.1016/j.techfore.2018.12.004

Kock, N., Auspitz, C., \& King, B. (2000). Using the web to enable industry-university collaboration: An action research study of a course partnership. Informing Science: the International Journal an Emerging Transdiscipline., 3(3), 157-166. https://doi.org/10.28945/591

Kolmos, A., Kofoed, L. B., \& Du, X. Y. (2008). PhD students' work conditions and study environment in university-and industry-based PhD programmes. European Journal of Engineering Education, 33(5-6), 539-550. https://doi.org/10.1080/03043790802588383

Kunttu, L., Huttu, E., \& Neuvo, Y. (2018). How doctoral students and graduates can facilitate boundary spanning between academia and industry. Tecbnology Innovation Management Review, 8(6), 48-54. https://doi.org/10.22215/timreview/1164

Larsson, J., \& Holmberg, J. (2018). Learning while creating value for sustainability transitions: The case of Challenge Lab at Chalmers University of Technology. Journal of Cleaner Production, 172, 4411-4420. https://doi.org/10.1016/i.jclepro.2017.03.072

Lind, F., Styhre, A., \& Aaboen, L. (2013). Exploring university-industry collaboration in research centres. European Journal of Innovation Management, 16(1), 70-91. https://doi.org/10.1108/14601061311292869

Linneberg, M. S., \& Korsgaard, S. (2019). Coding qualitative data: A synthesis guiding the novice. Qualitative Research Journal, 19(3), 259-270. https://doi.org/10.1108/qri-12-2018-0012

Lundin, J., Svensson, L., Lundh-Snis, U., \& Pareto, L. (2008). Practice based design for learning at work. International Journal of Advanced Corporate Learning (iJAC), 1(2), 17-23. https://doi.org/10.3991/ijac.v1i2.620

Malfroy, J. (2011). The impact of university-industry research on doctoral programs and practices. Studies in Higher Education, 36(5), 571-584. https://doi.org/10.1080/03075079.2011.594594

Metcalfe, J. S. (2006). Innovation, competition, and enterprise: Foundations for economic evolution in learning economies, In J. Hage \& T. Meeus (Eds.), Innovation, science, and institutional change: a research bandbook (pp. 105-121). Oxford University Press.

Morris, Z. S., Wooding, S., \& Grant, J. (2011). The answer is 17 years, what is the question: Understanding time lags in translational research. Journal of the Royal Society of Medicine, 104(12), 510-520.

https://doi.org/10.1258/jrsm.2011.110180 
Olsson, A. K., Arvemo, T., \& Bernhard, I. (2019). Bachelor students in research projects: Boosting WIL and university-society collaboration. INTED2019, 13th annual International Technology, Education and Development Conference, Valencia, 11th, 12th and 13th of March, 2019 (pp. 3015-3021). https://doi.org/10.21125/inted.2019.0796

Olsson, A. K., \& Bernhard, I. (2020). University-industry collaboration in higher education - Industry views on investing in industrial PhD students. Proceedings of EDULEARN2020, 12th annual International Conference on Education and New Learning Technologies, 6th - 7th of July, 2020, Mallorca, Spain, pp. 6726-6733. https://doi.org/10.21125/edulearn.2020

Olsson, A. K., Bernhard, I., Arvemo, T., \& Lundh Snis, U. (2020). A conceptual model for university-society research collaboration facilitating societal impact for local innovation. European Journal of Innovation Management. Advance online publication. https://doi.org/10.1108/EJIM-04-2020-0159

Patrick, C. J., Peach, D., Pockknee, C., Webb, F., Fletcher, M., \& Pretto, G. (2008). The WIL (work integrated learning) report: A national scoping study. Australian Learning and Teaching Council (ALTC) Final report. http://hdl.voced.edu.au/10707/228658

Rampersad, G. C. (2015). Developing university-business cooperation through work-integrated learning. International Journal of Technology Management, 68(3-4), 203-227. https://doi.org/10.1504/ijtm.2015.069664

Roolaht, T. (2015). Enhancing the industrial $\mathrm{PhD}$ programme as a policy tool for university-industry cooperation. Industry and Higher Education, 29(4), 257-269. https://doi.org/10.5367/ihe.2015.0259

Selsky, J. W., \& Parker, B. (2005). Cross-sector partnerships to address social issues: Challenges to theory and practice. Journal of Management, 31(6), 849-873. https://doi.org/10.1177/0149206305279601

Swedish Higher Education Authority. (2019). Higher Education Institutions in Sweden: 2019 Status Report. Report 2019:12. https://english.uka.se/about-us/publications/reports--guidelines/reports--guidelines/2019-0814-higher-education-institutions-in-sweden---2019-status-report.html

Tavares, O., Soares, D., \& Sin, C. (2020). Industry-university collaboration in industrial doctorates: A troublefree marriage? Industry and Higher Education, https://doi.org/10.1177/0950422219900155

Thune, T. (2009). Doctoral students on the university-industry interface: A review of the literature. Higher Education, 58(5), 637. https://doi.org/10.1007/s10734-009-9214-0

\section{BIOGRAPHIES}

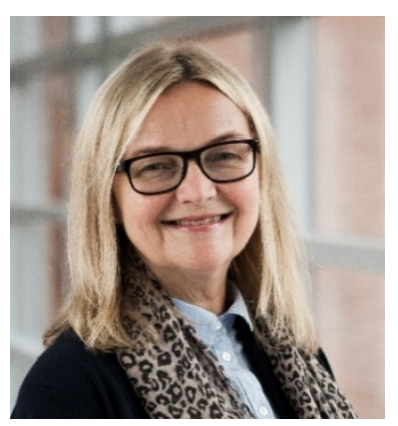

Dr. Irene Bernhard is an Assistant Professor in Informatics at School of Business, Economics and IT, University West, Sweden. This university has a special profile in work-integrated learning. She holds a PhD in planning and decision analysis from the Royal Institute of Technology, Stockholm, Sweden. During 2015-2020 she was deputy head of School of Business, Economics and IT, with special responsibility for research. Her research focuses on different aspects of the effects of digitalization as well as on work-integrated learning. Recent publications cover issues such as research on university-society research collaboration, digitalization, and network collaboration for local and regional development.

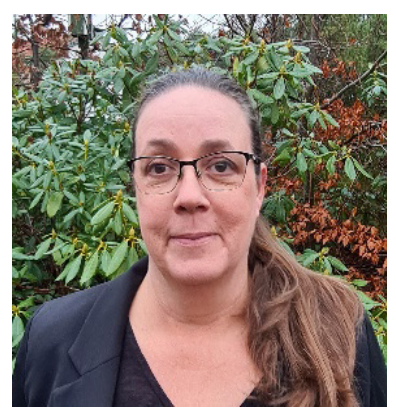

Dr. Anna Karin Olsson is an Assistant Professor in Business Administration at School of Business, Economics and IT, University West in Sweden. This university has a special profile in work-integrated learning. Anna Karin has a doctoral degree in business administration from School of Business, Economics and Law, University of Gothenburg in Sweden. She teaches at all levels from bachelor to $\mathrm{PhD}$. Recent publications cover issues such as university-society research collaboration, work-integrated learning, cultural heritage and urban regeneration, networking, stakeholder collaboration, social media, women entrepreneurs, and digitalization. 